\title{
Recurrent Laryngeal Nerve Injury With Versus Without Nerve Identification In Different Thyroidectomy Procedures
}

\author{
Saad Ramadhan Jawad *, Hadi Salman Hassan **
}

\section{ABSTRACT}

Background: The world health organization estimates that worldwide 2 billion people still have iodine deficiency Objectives: Is to make comparison between the effect of identification of recurrent laryngeal nerve (RLN) and nonidentification of the nerve on incidence of recurrent laryngeal nerve injury (RLNI) in different thyroidectomy procedures.

Type of the study: cross -sectional study.

Methods: 132 patients with goiters underwent thyroidectomy Identification of RLN visually by exposure were done for agroup of them and non-identification of the nerves for the other group. The outcomes of RLNI in the two groupsanalyzed statistically for the effect of Identification of RLN on decreasing the incidence of the nerveinjury .The benefits of identification of RLN evaluated in each procedure ofthyroidectomy which were total thyroidectomy (TT), near totalthyroidectomy (NTT), and subtotal thyroidectomy (STT).Patients were followed up monthly for 6 months by indirect laryngoscopy for mobility of the vocal cords.

Results: 132 patients underwent thyroidectomy,258 RLNswere at risk, 124 nerves were identified and134 nerves were not identified, $1 \mathrm{RLN}$ was injured in identified group, and $8 \mathrm{RLN}$ were injured in non-identified group. The pvalue was $(0.0393)$ which was significant. TT were performed for 56 patients $(42.4 \%)$ and total hemi thyroidectomy(THT) for 6 patients(4.5\%), there were 118
RLNs at risk, 64RLNs were identified and 54 RLNs were not identified.1RLN was injured in identified group, and 7RLNs were injured in non-identifiedgroup, the pvalue was $(0.023)$ which was significant.NTT procedure were performed for 38 patients(28.8\%), $76 \mathrm{RLNs}$ were at risk. 30 RLNswere identified and none of themwas injured, 46 RLNswere not identified, $1 \mathrm{RLN}$ was injured the $\mathrm{p}$ value was(1)which was not significant.STT were performed for 32patients(24.4\%),64 RLNs were at risk. $30 \mathrm{RLNs}$ were identified and 34 RLNs not identified,there was no nerve injury in both groups .

Conclusions: identification of RLN decrease incidence of RLNI in TT, while there was no significant increase of RLNI in NTT and STT when the nerve was not identified

Keywords: thyroid gland, thyroidectomy, recurrent laryngeal nerve and recurrent laryngeal nerve injury.

\section{Al-Kindy College Medical Journal 2018: Vol. 14 No.1} Page: 29-32

*MBCHB .FICMS. General surgeon,Al-imam Ali hospital mob.07731193961,Email.Saadjawad665@yahoo.com ** MBCHB . FICMS,CABM. Otolaryngologist,Al-imam Ali hospital mob. 07901856552, Email.Hadisalman61@yahoo.com

Received $13^{\text {th }}$ Jan 2017, accepted in final $30^{\text {th }}$ Oct 2017 Corresponding to: Saad Ramadhan Jawad, email: Saadjawad665@yahoo.com, mobile:07731193961
$\mathrm{T}$ he world health organization estimates that worldwide 2 billion people still have iodine deficiency ${ }^{(1)}$.Astudy in Iraq 1992 showed 41.7\% of women childbearing age got goiter, and in 1993, another study showed $24-44 \%$ of school age children got goiter ${ }^{(\tau)}$.A random study from Hilla city involving 12 female secondary schools showed goiter in $22 \%$ in school age females in Hilla city in Iraq ${ }^{(\Upsilon)}$. Thereare different techniques of thyroidectomy either subtotal,neartotal,total, hemithyroidectomy, total thyroidectomy with lymph node sampling or total thyroidectomy with neck dissection for malignancy. The most important complication that may occur during thyroidectomy is RLNI with its serious outcome of hoarseness of the voice, aphonia, dyspnea and the patient may end with tracheostomy. All surgeons whoperform thyroidectomy are worried about preserving RLN during thyroidectomy. Different techniques are performed to preserve it.In our study we compared the incidence ofRLNI in different types of thyroidectomy when we identified the RLN visually by dissection or not identified the nerve.
Methods: This was a prospective study conducted in department of surgery at Al-Imam Ali hospital in Baghdad for a period of 4 years from $1^{\text {st }}$ March 2012 to $30^{\text {th }}$ April 2016.Total of 132 patients with goiters underwent thyroidectomy and operations were performed by the same surgeon .patients that had RLN palsy was excluded from this study.All patients were evaluated preoperatively for thyroid function test, fine needle aspiration cytology, ultrasound scan of the neck, serumcalcium, X-ray of the neck and other routine investigations. Preoperative indirect laryngoscopy to assess status of vocal cords, they were bilaterally mobile in all patients. The operations were performed under general anesthesia using endotracheal tube. Classical open thyroidectomy, strap muscles were divided at their upper extremity in some cases according to visibility of the field and size of the goiter. Ligation and transection of superior thyroid artery and veinclose to the superior pole of thyroid parenchyma, middle thyroid vein if present, and the inferior thyroid vein. Different types of thyroidectomy were performed according to the preoperative evaluation, TT, NTT, STTor THT. The RLN 
identified visually in agroup of the patients and not identified in the other group, attempts were made to identify the RLN in allTT and NTT procedures and those RLN which not identified in these types of surgery it was because of difficulty. Surgeons may use different landmarks for identification of RLN depending on their experiences. The RLN may be identified using Simon triangle as a landmark ${ }^{(4)}$.The other landmark is the inferior parathyroid gland and middle thyroid vein ${ }^{(5)}$.superior parathyroid gland and zuckerkandl tubercle also can be used for searching for RLNWhich can be identified below this landmark ${ }^{(6)}$.Some surgeons used to identify the RLN.at its distal end at cricoid cartilage ${ }^{(7)}$. In thisstudy when recurrent laryngeal nerve wasidentified, the technique was a systematic search for RLN in a Simon's triangle using a trachea-esophageal groove as a landmark with a blunt dissection and avoidance of electro-coagulation, and the nerve followed higher up when identified. In TT and NTT the thyroid gland resected using Bi-polar electrocoagulation while in STT we used to resect the gland with a blade and suturing the remnant with absorbable suture. The patients were followed monthly for 6 months by indirect laryngoscopy for RLNI.Comparison was done between the two groups regarding the benefit of identification of $R L N$ on decreasing the incidence of RLNI in the total patients, and in each type of thyroidectomy. The data analyzed statistically using fisher's exact test.

Results: Total 132 patients underwent thyroidectomy. $85(64.4 \%)$ were females and $47(34.6 \%)$ were males. Ages were ranging from 17 to 63 years; the mean was 37.35 years $(S D \pm 8.37)$. Disorders of thyroid glands andthe types of thyroidectomywhich performed shown in table 1.

Table -1- Thyroid disorders with types of thyroidectomy procedures

\begin{tabular}{|c|c|c|c|c|c|}
\hline \multirow[t]{2}{*}{$\begin{array}{l}\text { Thyroid } \\
\text { disorders }\end{array}$} & \multirow[t]{2}{*}{$\begin{array}{c}\text { Number } \\
\text { of } \\
\text { patients }\end{array}$} & \multicolumn{4}{|c|}{$\begin{array}{c}\text { Types of thyroidectomy } \\
\text { procedure }\end{array}$} \\
\hline & & TT & NTT & STT & THT \\
\hline $\begin{array}{l}\text { Benign } \\
\text { multinodul } \\
\text { ar }\end{array}$ & 87 & 25 & 30 & 32 & 0 \\
\hline $\begin{array}{l}\text { Toxic } \\
\text { goiter }\end{array}$ & 20 & 12 & 8 & 0 & 0 \\
\hline $\begin{array}{l}\text { single lobe } \\
\text { cyst }\end{array}$ & 5 & 0 & 0 & 0 & 5 \\
\hline $\begin{array}{l}\text { Suspicious } \\
\text { of } \\
\text { malignanc } \\
y\end{array}$ & 13 & 12 & 0 & 0 & 1 \\
\hline $\begin{array}{l}\text { Recurrent } \\
\text { goiter }\end{array}$ & 7 & 7 & 0 & 0 & 0 \\
\hline Sum & 132 & 56 & 38 & 32 & 6 \\
\hline
\end{tabular}

87 patients with benign euthyroid multinodular goiter, TT were performed for 25, NTT for 30 and STT for 32 patients. 20 patients with toxic goiters, 12 of them underwent TT and NTT performed for remaining 8 patients. All 7patients with recurrent goiters submitted to TT. Suspicion of malignancy either by ultrasound or fine needle aspiration cytology was found in 12 patients and TT were done for all. Malignancy proved by histopathology for 7 of them postoperatively. THT were done for 6 patients for cystic degeneration in 5 and suspicious nodule in 1 . The effect of RLN identification on decreasing the incidence of RLNI in each type of thyroidectomy procedure is shown in table 2.

Table-2-Types of thyroidectomy with significance of RLN Identification on incidence of RLNI

\begin{tabular}{|c|c|c|c|c|c|c|c|}
\hline $\begin{array}{l}\text { Type } \\
\text { of } \\
\text { thyroi } \\
\text { decto } \\
\text { my }\end{array}$ & $\begin{array}{l}\text { No of } \\
\text { patie } \\
\text { nts }\end{array}$ & $\begin{array}{l}\text { Ns at } \\
\text { risk }\end{array}$ & $\begin{array}{c}\text { Gr } \\
\text { ou } \\
\text { pA } \\
\text { Ns } \\
\text { Ide } \\
\text { nt }\end{array}$ & $\begin{array}{c}\text { Ns } \\
\text { inj } \\
\text { ure } \\
\text { d } \\
\text { in } \\
\text { gro } \\
\text { up } \\
A\end{array}$ & $\begin{array}{c}\text { Grou } \\
\text { pB } \\
\text { Ns } \\
\text { not } \\
\text { Ident }\end{array}$ & $\begin{array}{c}\text { Ns } \\
\text { injured } \\
\text { in } \\
\text { groupB }\end{array}$ & 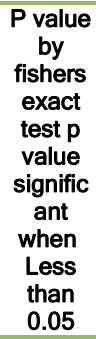 \\
\hline $\begin{array}{c}\mathrm{TT} \\
+\mathrm{TH} \\
\mathrm{T}\end{array}$ & $\begin{array}{r}56+ \\
6\end{array}$ & 118 & 64 & 1 & 54 & 7 & 0.023 \\
\hline NTT & 38 & 76 & 30 & 0 & 46 & 1 & 1 \\
\hline STT & 32 & 64 & 30 & 0 & 34 & 0 & 1 \\
\hline $\begin{array}{c}\text { All } \\
\text { patie } \\
\text { nts }\end{array}$ & 132 & 258 & $\begin{array}{c}12 \\
4\end{array}$ & 1 & 134 & 8 & 0.0393 \\
\hline
\end{tabular}

TT was done for 56patients and THT for 6 patients. There were $118 \mathrm{RLNs}$ at risk, 64 nerves were identified with unilateral RLNI (1.56\%)and vocal cord movement improved after 4 months follow up, while 54 RLNs not Identified had 7 RLNI (12.96\%)immediately postoperatively 4 of them improved within 3 to 5 months unfortunately 3 of them remainedpermanently affected after 6 months follow up. The result was Identification of RLN in TT significantly decrease RLNI $p$ value $(0.023)$. NTT was performed for38 patients with 76 RLNs were at risk.30 nerves were identified with no RLNI, and 46 nerveswere not identified, only one RLN injured (2.17\%) and remainedpermanent after 6 months follow. The result was that non identification of recurrent laryngeal nerve in NTT procedure does not increase significantly the RLNI. The remaining 32 patients underwent STT, with nerves at risk were 64.Identification of the 30 $\mathrm{RLN}$, and 34 were not Identified. There was no RLNI in both groups, so the Identification of RLN in STT does not affect theincidence of RLNI. The overall patients 132 with nerves at risk were 258 nerves, Identification of 124 nerves with RLNI for only $1(0.8 \%)$. Non Identification of 134 nerves with 8 of total gotinjured $(5.97 \%)$. The $p$ value was (0.0393) which is significant.None of the patients got bilateral RLNI and none of them needed tracheostomy. Most of RLNI 5 of 9 occurred in reoperation TT for recurrent multinodular goiters, inwhich RLN was not identified because of difficulty.unilateral vocal cord immobility noticed by 
anesthetist in 7 patients at the time of extubation and the other 2 patients got change of voice at the $1^{\text {st }}$ postoperative day and a unilateral immobile vocal cord seen by indirect laryngoscopy. The follow up of the patients for indirect laryngoscopy was difficult, all patients with normal vocal cord movement stopped attending follow up after one to four months except for six of them completetheir follow up period and they remained normal after 6 months follow up.For those with unilateral vocal cord palsy two of them were stopped attending after their vocal cord movement improved within five months, the remaining completed their follow up period. We found that 4 of the total 9 unilateral RLN palsy $44.4 \%$ remainedpermanent.

\section{Discussion:}

RLNI is one of a serious complication after thyroidectomy. It's an embarrassing situation and may carry a medico legal dilemmafor the surgeon.Arguments are still rising about the thyroidectomy procedurethat should be performed, total or incomplete thyroidectomy for the hope of avoidance of the recurrence of goiter and prevention of thyroidectomy complications. This article is designed to view the effect of identification of RLN on reducing the $\mathrm{RLNI}$ and whether it isamustor not to expose the RLN in different thyroidectomy procedures, total, near total, or subtotal.The first surgeon who advocated routine dissection and demonstration of the nerves in 1911 was August Bier of Berlin: he was followed by Frank Lahey of Boston in $1938^{(10)}$. Titch showed that thyroidectomy account for $35.71 \%$ of surgical causes of RLNI and $3.73 \%$ of all causes $^{(11)}$.Studies in different theses showed incidence of RLNI varied between $1.5-14 \%{ }^{(12)}$. Matthias Echternach etal showed that 78 patients got unilateral and 6 patients got bilateral nerve palsy out of 1365 nerves at risk $6.6 \%{ }^{(13)}$. In present study we found that the incidenceof permanent RLNI was $1.55 \%$. We found asignificant difference of RLNI in the group of thyroidectomy in which RLN identified and whenit was not Identified $0.8 \%$ and $5.97 \%$ respectively. Several others studies agreed with this result ${ }^{(14,15,16,17)}$. However some other studies showed no difference in outcome of RLNI whether dissected completely or partially or not dissected (13, ${ }^{18)}$.In this study we observed that in STT there was no RLNI when the nerve identified or not. Zahid Anwar, et al, from Pakistan also showed no difference in the frequencies of RLNI when nerve identified or not in subtotal thyroidectomy ${ }^{(19) .}$ Saadeldin, et al, fromSudan advocated for routine identification of RLN in subtotal

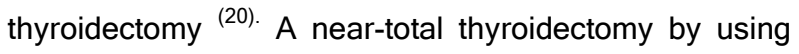
capsular dissection leaving a few grams of thyroid tissue at a ligament of Berry and the site of entrance of inferior thyroid artery branches, the study showed no significant difference when the RLN identified or not, and this is matched with a study from Hyderabad by Fazila Hashmi, et al, which showed RLNI in near total thyroidectomy was $4.5 \%$ when the nerve identified and $9 \%$ in non- identified nerves, it was not significant statistically. The group claimed that the extent of the surgery affect RLNI not the identification of the nerve ${ }^{(21)}$.Hazem M Zakaria, etal, found out that no RLNI in near totalthyroidectomy (12). We found out that the incidence of RLNI greatly decreased in TT when the nerve identified versus not identified, $1.59 \%$ and $12.95 \%$ respectively. Many articles match with this result.Hakan Canbez,et al showed $0 \%$ of RLNI inTT when RLN identified and $7.9 \%$ when not identified $^{(22)}$.A study from Philippine showed even higher incidence, $30 \%$ when RLN not identified in TT ${ }^{(23)}$.It was reported that revision surgery significantly increase the rate of $\mathrm{RLNI}$ (12, 24,25.) .In present study , revision surgery was performed for only 7 patients ,unilateral permanent RLNI for 2 of them ,it was difficult to identify the RLN due to lost anatomical land marks .The permanent RLNI occurred in TT 3 out of 7 injured nerves when the RLN not identified, while there was no permanent RLNI when the nerve identified this is also was seen by Chiang,et al, they showed that most of $\mathrm{RLNI}$ in total lobectomy when the nerve identified recovered within 4 months ${ }^{(26)}$.

Conclusions: Non exploration of RLN in subtotal and near total thyroidectomy does not significantly increase $\mathrm{RLNI}$. In total thyroidectomy RLNI greatly reduced when the nerve identified, nerve identification and protection should be attempted in every total thyroidectomy. Revision thyroidectomy for recurrent benign goiters with difficult exploration of the RLN, near total or capsular dissection thyroidectomy is a better alternative to decrease the possibility of RLNI.

\section{References}

1- Mark PJ Vanderpump,Commentory:lodine deficiency as a new challenge for industrialized countries: AUK perspective.International Journal of Epidemiology.2012;41(3):601-6042-Fereidoun Azizi(ICCIDD).Current status of lodine Nutrition in Iraq.IDD Newsletter.2010; 36:number 2

2- Hussian.S.Al-Janabi,Hassan A H,Ahmed T N.Prevalence of goiter among secondary school female students in Hilla city,Iraq during year 2002.Iraqi Comm.Med.J ;17(1):66-71.

3- Mohebati A, Shaha A R. Anatomy of thyroid and parathyroid glands and neurovascular relations. Clin.Anat. 2012; 25(1):19-31.

4- Chenling Shen, Mingliang Xiang, Hao Wa, Yan Ma, Li Chea, Lun Chen. Routine exposure of recurrent laryngeal nerve in thyroid surgery,can prevent nerve injury?.Neural Research.2013;8(17):1568-1578.

5- Mozumder S, Dubey S, A Dam, A K Bhowmick.Identifying recurrent laryngeal nerve in thyroid surgery using relationship with superior parathyroid gland and tubercle of zuckerkandl.Bengal journal ofotolaryngology and head-neck surgery. 2015;23(3):99-103. 
6 -Maisiel L Shindo, James C Wu, Eunice Epark. Surgical anatomy of the recurrent laryngeal nerve revisited. Otolaryngology-head and neck surgery.2005;133(4):514-519.

7- Daniel Oertli ,Robert Udelsman.Surgery of the thyroid and parathyroid glands.2007; Chap 17: page 219

8- Titche LL.Causes of recurrent laryngeal nerve paralysis.Ach-otolaryngol 1976;102(5):259-261.

9- Hazem M Zakaria,Naif A Al Awad,Ali S Al Kreedes, etal.Recurrent laryngeal nerve injury in thyroid surgery.Oman.Med J.2011;26(1):34-38.

10- Echternach M,Maurer C A,Mencke T,Schilling M,Verse T,Richter B. Laryngeal complications after thyroidectomy, Is it always the surgeon?.Arch Surg.2009;144(2):149-53.

11- Yan J,Bo G,Xiaohua Z,Jianjie Z,Jinping C, Shu Z ,Donglin L. Prevention and treatment of recurrent laryngeal nerve injury in thyroid surgery.Int .J.clin Exp Med.2014;7(1):101-107

15- Aytac B, Karamercan A; Recurrent laryngeal nerve injury and preservation in thyroidectomy.SaudiMed J.2005; 26(11):1746-9

16- Acun Z,Cinar F, Cihan A, Ulukent SC,Uzun L, Ucan B ,Uqur MB.Importance of identifying the course of the recurrent laryngeal nerve in total and near total thyroid lobectomy. Am Surg.2005 ;71(3):225-227.

17- Ihsan HS, Hayder SS, Jassem AlBedri.Thyroidectomy with or without recurrent laryngeal nerve exposure Iraqi.J.Comm.Med.2013;( 2): 188-191.

18-Abdulameer MA, Asaad MK .Recurrent laryngeal nerve injury during thyroid surgery .Thi-Qar Medical Journal .2015; 10 (2).
19-Zahid Anwar, Omer Bin Abdul Aziz, Zaka Ullah Malik, Saad Ahmad Malik, Javaid Iqbal, Junaid Mansoor. Frequency of vocal cord injury with identification of recurrent laryngeal nerve and without identification of recurrent laryngeal nerve during subtotal thyroidectomy. Pak Armed Forces Med J .2015 65(2): 227-30.

20-Saadeldin Al, QurashiMA, Aamir AH .Incidence of recurrent laryngeal nerve injury during thyroid surgery. Sch.J.App.Med.Sci. 2013; 1(6):673-677.

21-Fazila H, FaisalGS, Abdul Sattar MA .Is thyroidectomy safe after identification of recurrent laryngeal nerve-fact or fiction.Pak J Med Res.2010; 49(4):131-133.

22-Hakan C,Musa D ,Tahsin C ,Koray O,Tamer A ,Oner B ,Bahar T , Suha A .Total thyroidectomy is safer with identification of recurrent laryngeal nerve.J Zhejiang univ sci B.2008;9(6):482-488.

23-Andrie Jeremy Formanes, MD.Vocal fold paralysis with intraoperative recurrent laryngeal nerve identification versus non identification of recurrent laryngeal nerve. Philippine Journal of Otolaryngology-Head and Neck Surgery.2016; 31(1):22-25.

24-Chan WF, Lang BH, Lo CY .The role of intraoperative neuromonitoring of recurrent laryngeal nerve during thyroidectomy: acomprative study on 1000 nerves at risk.Surgery.2006; 140(6):866-872.

25-Patrick S, Ann O C, Matthew S M. Risk factors for recurrent laryngeal nerve neuropraxiapost thyroidectomy. Otolaryngology-Head and Neck Surgery.2012; 146(6): 900-905.

26-Chiang $F Y$, Wang L F, Huang $Y F$, Lee K W, Kuo W R. Recurrent laryngeal nerve palsy after thyroidectomy with routine identification of recurrent laryngeal nerve. Surgery. 2005;137(3):342-347. 